\title{
Avaliação alelopática de extratos etanólicos de Copaifera sabulicola sobre o desenvolvimento inicial de Lactuca sativa, Lycopersicum esculentum e Zea mays
}

\author{
Manoel Viana Linhares Neto \\ Farley Silva Santana \\ Rafael Soares Pozzi Malheiros \\ Luciana Lucas Machado \\ Ana Maria Mapeli * \\ Universidade Federal da Bahia, Instituto de Ciências Ambientais e Desenvolvimento Sustentável \\ Campus Reitor Edgard Santos, CEP 47800-000, Barreiras - BA, Brasil \\ * Autor para correspondência \\ amapeli@pop.com
}

Submetido em 29/05/2013

Aceito para publicação em 26/05/2014

\section{Resumo}

Este trabalho objetivou avaliar o potencial alelopático de extratos etanólicos do caule e das folhas de Copaifera sabulicola, sobre a germinação de sementes e o crescimento de plântulas de Lactuca sativa e Lycopersicum esculentum, bem como avaliar o efeito alelopático desses extratos sobre a germinação e o crescimento de plântulas de Zea mays, a partir de bioensaios em condições de laboratório. Os extratos foram testados nas concentrações $0,250,500$ e $1.000 \mathrm{mg}$. $\mathrm{L}^{-1}$. Avaliou-se a porcentagem de germinação, velocidade média de germinação, índice de velocidade de germinação e comprimento médio das plântulas. Todos os parâmetros foram submetidos à análise de variância, sendo as médias comparadas pelo teste $\operatorname{Scott-Knott~}(\mathrm{p} \leq 0,05)$. Verificouse que, em L. sativa, o extrato do caule promoveu estímulos significativos na porcentagem de germinação e no crescimento radicular, enquanto o extrato foliar estimulou somente o crescimento radicular. Em L. esculentum, o extrato do caule promoveu estímulos significativos no crescimento do hipocótilo e radicular, já o extrato foliar estimulou somente o crescimento radicular. Em Z. mays, ambos os extratos inibiram significativamente a germinação. Portanto, constatou-se o potencial alelopático dos extratos etanólicos de C. sabulicola sobre $L$. sativa e L. esculentum, bem como o efeito alelopático inibitório sobre Z. mays.

Palavras-chave: Bioensaios; Cerrado; Germinação; Metabólitos secundários

\section{Abstract}

Allelopathic evaluation of ethanol extracts of Copaifera sabulicola on the initial development of Lactuca sativa, Lycopersicum esculentum, and Zea mays. This paper aimed to evaluate the allelopathic potential of ethanol extracts from stem and leaves of Copaifera sabulicola on seed germination and seedling growth of Lactuca sativa and Lycopersicum esculentum, as well as to evaluate the allelopathic effect of these extracts on seedling germination and growth of Zea mays, through bioassays under laboratory conditions. The extracts were 
tested at the concentrations $0,250,500$, and 1,000 $\mathrm{mg} . \mathrm{L}^{-1}$. We evaluated the germination percentage, germination average speed, germination speed index, and seedling average length. All parameters underwent variance analysis, and the mean values were compared by means of Scott-Knott test ( $\mathrm{p} \leq 0.05)$. We found out that, in $L$. sativa, the extract from stem promoted significant stimuli on germination percentage and root growth, while the extract from leaves only stimulated root growth. In L. esculentum, the extract from stem promoted significant stimulus on hypocotyl and root growth, in turn, the extract from leaves stimulated only root growth. In $Z$. mays, both extracts significantly inhibited germination. Therefore, we found out the allelopathic potential of ethanol extracts of C. sabulicola on L. sativa and L. esculentum, as well as inhibitory allelopathic effect on Z. mays.

Key words: Bioassays; Cerrado; Germination; Secondary metabolites

\section{Introdução}

No reino vegetal, o desenvolvimento evolutivo de rotas biossintéticas, a partir do metabolismo primário, determinou a produção de compostos secundários com diversas funções fisiológicas (TAIZ; ZEIGER, 2013). Os efeitos diretos ou indiretos, benéficos ou maléficos, de substâncias oriundas do metabolismo secundário vegetal constituem o objeto de estudo da alelopatia em agrossistemas, área emergente da ecofisiologia, sendo denominados de aleloquímicos aqueles metabólitos que causam estímulo, inibição e/ou dano nos seres vivos adjacentes (FERREIRA; ÁQUILA, 2000).

Os aleloquímicos são sintetizados tanto em órgãos vegetativos como reprodutivos, podendo ser liberados através de lixiviação, volatilização, decomposição e exsudação radicular. A produção dos aleloquímicos depende das características físicas e biológicas do ambiente (SOUZA et al., 2006), além de ser particular entre grupos taxonômicos. A ação dessas substâncias representa uma adaptação evolutiva dos vegetais, com intuito de combater diversas interferências, como herbivoria, infecções por micro-organismos e competição planta-planta (TAIZ; ZEIGER, 2013).

As pesquisas em alelopatia podem subsidiar estratégias sustentáveis na agricultura, uma vez que os aleloquímicos têm sido objetos de estudos na busca de novas substâncias e melhor compreensão dos seus efeitos sobre áreas cultivadas (PERES et al., 2009). Deste modo, a alelopatia é útil para identificação de fitotoxinas e de derivados sintéticos a serem empregados como herbicidas, inseticidas, fungicidas e nematicidas naturais (BORELLA; PASTORINI, 2009).
Vale destacar que, diante da rápida redução das áreas do Cerrado brasileiro, principalmente devido à expansão do agronegócio, é importante o incentivo aos estudos referentes à biodiversidade, bem como às interações ecológicas, incluindo a alelopatia na detecção preliminar de substâncias bioativas, agregando valor fitoquímico às espécies desse domínio fitogeográfico.

Dentre as espécies nativas do Cerrado, destaca-se a Copaifera sabulicola J.A.S. Costa \& L.P. Queiroz (Leguminosae, Caesalpinioideae, Tribo Detarieae), a qual foi identificada como uma nova espécie, provavelmente endêmica do centro-oeste da Bahia e do extremo norte de Minas Gerais. Possui hábito arbóreo ou arbustivo, distinguindo-se dos demais táxons incluídos em Copaifera L. por apresentar uma combinação de caracteres, tais como: ramos, folhas e folíolos glabros a glabrescentes, raramente pubérulo; folhas, geralmente, sésseis a pecioladas (no mesmo espécime), folíolos com (1)-2-3 pares com ápice obtuso e emarginado, pontuações translúcidas presentes em toda a lâmina; flores e frutos, geralmente, pedicelados (COSTA; QUEIROZ, 2007).

Embora taxonomicamente descrita, não há informações sobre as potencialidades fitoquímicas e alelopáticas desta espécie. Não obstante, o gênero Copaifera L. já é reconhecido como fonte de princípios ativos provenientes do óleo exsudado do tronco dessas plantas, a partir do qual já foram constatadas propriedades farmacológicas e biocidas (VEIGA-JÚNIOR; PINTO, 2002; GERIS et al., 2008; SOUZA et al., 2011).

O potencial alelopático de uma planta doadora pode ser identificado através de bioensaios laboratoriais, utilizando-se espécies consideradas bioindicadoras, 
como alface (Lactuca sativa L.) e tomate (Lycopersicum esculentum Mill.), por serem mais sensíveis à resistência ou tolerância aos aleloquímicos (FERREIRA; ÁQUILA, 2000). Por conseguinte, outras espécies cultivadas podem ser utilizadas como espécies-teste em estudos sobre o efeito dos aleloquímicos, como o milho (Zea mays L.) (GOMES et al., 2013), o qual apresenta rápido e fácil desenvolvimento e, assim, fornecendo resultados em pouco tempo.

Neste contexto, em virtude da importância investigativa dos aleloquímicos no ambiente e do não conhecimento de C. sabulicola no âmbito da fisiologia vegetal, este trabalho teve como objetivo avaliar o potencial alelopático de extratos etanólicos do caule e das folhas da espécie, sobre a germinação de sementes e o crescimento de plântulas de L. sativa e L. esculentum, bem como avaliar o efeito alelopático desses extratos sobre a germinação de sementes e o crescimento de plântulas de Z. mays, a partir de bioensaios, em condições de laboratório.

\section{Material e Métodos}

\section{Material vegetal}

Espécimes de C. sabulicola foram coletados no município de Barreiras (Bahia), km 40 da BR 242, $12^{\circ} 05^{\prime} \mathrm{S}, 45^{\circ} 22^{\prime} \mathrm{W}$, sentido Luís Eduardo Magalhães, BA, tendo como estruturas-alvo cascas do caule e folhas completamente expandidas. O período de coleta ocorreu no mês de janeiro de 2010, em que a planta se apresentava em estádio reprodutivo.

\section{Preparo dos extratos}

Os extratos foram preparados no laboratório de química orgânica do Instituto de Ciências Ambientais e Desenvolvimento Sustentável (ICADS) da Universidade Federal da Bahia (UFBA). Para tanto, os materiais coletados referentes ao caule $(400 \mathrm{~g})$ e as folha $(500 \mathrm{~g})$ foram desidratados ao ar, triturados, macerados e, em seguida, submersos em álcool etílico 95\%, separadamente. Realizou-se a filtragem após sete dias, com três extrações. A solução etanólica foi concentrada em pressão reduzida, utilizando-se evaporador rotativo, a $65^{\circ} \mathrm{C}$. Assim, obteve-se o extrato etanólico bruto do caule $(6,3 \mathrm{~g})$ e da folha $(4,8 \mathrm{~g})$, os quais foram testados nas seguintes concentrações: 0, 250, 500 e 1.000 mg.L1 (MELOS et al., 2007), sendo a maior concentração obtida por pesagem e as demais por diluição.

\section{Bioensaios de germinação e crescimento}

Os bioensaios foram conduzidos no laboratório de fisiologia vegetal (ICADS/UFBA), durante os anos de 2010-2012. Nos experimentos, utilizou-se sementes de alface - Lactuca sativa L. cv. Grand Rapids, tomate - Lycopersicum esculentum Mill. cv. Santa Clara (representantes de eudicotiledôneas), e milho-Zea mays L. cv. Havai (monocotiledônea), obtidas comercialmente. As sementes foram previamente desinfetadas com hipoclorito de sódio $2 \%$, por dois minutos, em seguida lavadas com água destilada.

Nos bioensaios com sementes de L. sativa e L. esculentum, utilizou-se placas de Petri $(9 \mathrm{~cm}$ de diâmetro), contendo dois discos de papel filtro qualitativo, impregnados com $2,0 \mathrm{~mL}$ da solução referente às concentrações $(0,250,500$ e 1.000 mg.L'). Após a evaporação do solvente, adicionou-se $2,5 \mathrm{~mL}$ de água destilada. Em seguida, 50 sementes foram distribuídas aleatoriamente em cada placa. Procedimento similar foi realizado com Z. mays, porém, utilizandose proporções diferentes devido ao maior tamanho das sementes. Assim, cada placa (12 cm de diâmetro) recebeu 25 sementes, $5 \mathrm{~mL}$ da solução referente às concentrações, sendo umedecida com $5 \mathrm{~mL}$ de água destilada. As placas de Petri foram acondicionadas em ambiente climatizado, a $25^{\circ} \mathrm{C}$, sob fotoperíodo constante de $24 \mathrm{~h}$ (BRASIL, 1992). Os discos de papel filtro foram mantidos úmidos, adicionando-se $2 \mathrm{~mL}$ de água destilada por dia, quando necessário. Os experimentos duraram sete e 16 dias para $L$. sativa e L. esculentum, respectivamente, e 11 dias para $Z$. mays.

A germinação foi analisada diariamente, tendo como critério a protrusão da radícula/raiz primária de $2 \mathrm{~mm}$ de comprimento (DURAN; TORTOSA, 1985). Considerou-se concluído o experimento quando a 
germinação foi nula por três dias consecutivos. Os dados foram avaliados quanto à porcentagem de germinação (PG), velocidade média de germinação (VMG) e índice de velocidade de germinação (IVG).

Os resultados quanto à $\mathrm{PG}$ foram submetidos à transformação:

$$
\operatorname{arcsen}\left(\sqrt{\frac{x}{100}}\right)
$$

Em que, $x$ representa a média de sementes germinadas em cada repetição.

A VMG foi determinada pelo produto entre a média do número de sementes germinadas das repetições, em cada tratamento, e o tempo, representado pelo respectivo dia de contagem das sementes.

A determinação do IVG das sementes foi realizada conforme Maguire (1962), por meio de contagens diárias do número de sementes germinadas:

$$
I V G=\frac{G 1}{N 1}+\frac{G 2}{N 2}+\ldots+\frac{G N}{N N}
$$

Posto que: G1, G2 e GN representam o número de sementes normais germinadas até o enésimo dia; N1, N2 e NN representam o número de dias em que se avaliaram as germinações G1, G2 e GN.

Em cada placa, dez plântulas foram selecionadas para a análise do comprimento da radícula/raiz primária e do hipocótilo/coleóptilo, sendo as medidas realizadas após o terceiro dia de germinação, com papel milimetrado (BARNES; SOEIRO, 1981).

Para a apresentação dos resultados, calculou-se a diferença, em porcentagem, de inibição/estímulo das médias das repetições em um ou mais tratamentos, a depender da semelhança estatística, em relação ao tratamento controle.

\section{Delineamento experimental}

Utilizou-se o delineamento experimental inteiramente casualizado, com quatro repetições, constituídas de 50 sementes de L. sativa/L. esculentum, 25 sementes de $Z$. mays e 10 plântulas para as medidas de crescimento, em cada placa. Os dados obtidos foram submetidos à análise de variância, sendo as médias comparadas pelo teste Scott-Knott a 5\% de probabilidade, por meio do Sistema de Análises Estatísticas e Genéticas - SAEG 9.1 (EUCLYDES, 1997).

\section{Resultados}

Nos resultados obtidos quanto à porcentagem de germinação (PG), verificou-se efeito significativo nas sementes de $L$. sativa somente quando submetidas ao extrato etanólico do caule, o qual promoveu estímulo médio de $1,8 \%$, em relação ao controle (Tabela 1). Tratando-se dos bioensaios com sementes

TABELA 1: Porcentagem germinação de sementes de Lactuca sativa, Lycopersicum esculentum e Zea mays, submetidas aos extratos etanólicos de Copaifera sabulicola. Barreiras, Bahia, Brasil, 2010-2012.

\begin{tabular}{cccc}
\hline \multicolumn{3}{c}{ Extrato do Caule } \\
\hline Concentração $\left(\mathbf{m g} . \mathbf{L}^{-1}\right)$ & L. sativa & L. esculentum & Z. mays \\
\hline Controle & $98,0 \mathrm{~B} \pm 0,82$ & $59,5 \mathrm{~A} \pm 4,99$ & $89,0 \mathrm{~A} \pm 1,91$ \\
250 & $100 \mathrm{~A} \pm 0,00$ & $64,0 \mathrm{~A} \pm 3,37$ & $72,0 \mathrm{~B} \pm 6,83$ \\
500 & $99,5 \mathrm{~A} \pm 0,50$ & $59,5 \mathrm{~A} \pm 0,96$ & $77,5 \mathrm{~B} \pm 6,61$ \\
1.000 & $100 \mathrm{~A} \pm 0,00$ & $66,0 \mathrm{~A} \pm 2,94$ & $87,0 \mathrm{~A} \pm 4,16$ \\
\hline \multicolumn{4}{c}{ Extrato das Folhas } \\
\hline Controle & $98,0 \mathrm{~A} \pm 0,82$ & $59,5 \mathrm{~A} \pm 4,79$ & $89,0 \mathrm{~A} \pm 1,91$ \\
250 & $99,5 \mathrm{~A} \pm 0,50$ & $59,5 \mathrm{~A} \pm 2,75$ & $89,0 \mathrm{~A} \pm 3,00$ \\
500 & $99,5 \mathrm{~A} \pm 0,50$ & $66,0 \mathrm{~A} \pm 1,83$ & $84,0 \mathrm{~A} \pm 9,38$ \\
1.000 & $99,5 \mathrm{~A} \pm 0,50$ & $63,5 \mathrm{~A} \pm 2,06$ & $77,5 \mathrm{~B} \pm 7,37$ \\
\hline
\end{tabular}

Médias seguidas da mesma letra, na coluna, não diferem significativamente pelo teste de Scott-Knott ( $\mathrm{p} \leq 0,05)$. Média \pm erro. 
de $L$. esculentum, não foram constatadas alterações significativas para a PG (Tabela 1). Em Z. mays, o extrato do caule causou efeito alelopático somente nas concentrações 250 e $500 \mathrm{mg} . \mathrm{L}^{-1}$, havendo inibição média de $16 \%$. Já o extrato foliar apresentou efeito alelopático na germinação do Z. mays apenas na maior concentração (1.000 mg. $\left.\mathrm{L}^{-1}\right)$, a qual promoveu inibição de $13 \%$ (Tabela 1 ).

Os extratos etanólicos de C. sabulicola não influenciaram a velocidade média de germinação (VMG) das espécies testadas (Tabelas 2 e 3), bem como o índice de velocidade de germinação (IVG) de $L$. sativa e $L$. esculentum, uma vez que não foi observada diferença estatística entre as concentrações utilizadas. Entretanto, para Z. mays, o extrato do caule causou redução média significativa de $22 \%$ nas concentrações 250 e 500 mg.L ${ }^{-1}$ e o extrato foliar não interferiu significativamente no IVG das plântulas testadas (Tabela 4).

Diante das análises de crescimento, observou-se que as concentrações do extrato do caule promoveram aumento médio de $34 \%$ no comprimento radicular de L. sativa, em relação ao controle (Figura 1). Nos tratamentos com 250 e $500 \mathrm{mg} . \mathrm{L}^{-1}$ do extrato foliar, houve estímulo médio de $35 \%$ no crescimento, enquanto que, a concentração $1.000 \mathrm{mg} . \mathrm{L}^{-1}$ promoveu estímulo de $23 \%$. No entanto, o crescimento do hipocótilo de $L$. sativa não sofreu alterações significativas diante dos extratos utilizados (Figura 1).

TABELA 2: Velocidade média de germinação das sementes de Lactuca sativa, Lycopersicum esculentum e Zea mays, sob o efeito do extrato etanólicos do caule de C. sabulicola. Barreiras, Bahia, Brasil, 2010-2012.

\begin{tabular}{|c|c|c|c|c|c|c|c|c|c|c|c|c|c|c|c|}
\hline \multirow{3}{*}{$\begin{array}{l}\text { Concentração } \\
\left(\mathrm{mg} \cdot \mathrm{L}^{-1}\right)\end{array}$} & \multicolumn{14}{|c|}{ L. sativa } & \multirow[b]{3}{*}{15} \\
\hline & \multicolumn{14}{|c|}{ G.Dia ${ }^{-1}$} & \\
\hline & 1 & 2 & 3 & 4 & 5 & 6 & 7 & 8 & 9 & 10 & 11 & 12 & 13 & 14 & \\
\hline Controle & $45,5^{\text {ns }}$ & $47,8^{\mathrm{ns}}$ & $49,0^{\mathrm{ns}}$ & $49,0^{\mathrm{ns}}$ & $49,0^{\mathrm{ns}}$ & $49,0^{\mathrm{ns}}$ & $49,0^{\mathrm{ns}}$ & - & - & - & - & - & - & - & - \\
\hline 250 & $46,3^{\mathrm{ns}}$ & $49,3^{\mathrm{ns}}$ & $49,5^{\mathrm{ns}}$ & $49,5^{\mathrm{ns}}$ & $49,5^{\mathrm{ns}}$ & $49,5^{\mathrm{ns}}$ & $49,5^{\mathrm{ns}}$ & - & - & - & - & - & - & - & - \\
\hline 500 & $42,0^{\mathrm{ns}}$ & $49,0^{\mathrm{ns}}$ & $49,8^{\mathrm{ns}}$ & $49,8^{\mathrm{ns}}$ & $49,8^{\text {ns }}$ & $49,8^{\mathrm{ns}}$ & $49,8^{\mathrm{ns}}$ & - & - & - & - & - & - & - & - \\
\hline 1.000 & $46,5^{\text {ns }}$ & $48,3^{\mathrm{ns}}$ & $49,3^{\text {ns }}$ & $49,8^{\mathrm{ns}}$ & $49,8^{\text {ns }}$ & $49,8^{\text {ns }}$ & $49,8^{\text {ns }}$ & - & - & - & - & - & - & - & - \\
\hline \multicolumn{16}{|c|}{ L. esculentum } \\
\hline Controle & $0,0^{\text {ns }}$ & $1,5^{\mathrm{ns}}$ & $11,5^{\mathrm{ns}}$ & $23,0^{\mathrm{ns}}$ & $25,0^{\mathrm{ns}}$ & $27,5^{\text {ns }}$ & $28,0^{\mathrm{ns}}$ & $28,5^{\mathrm{ns}}$ & $28,8^{\text {ns }}$ & $28,8^{\mathrm{ns}}$ & $29,0^{\mathrm{ns}}$ & $29,0^{\mathrm{ns}}$ & $29,3^{\mathrm{ns}}$ & $29,3^{\mathrm{ns}}$ & $29,3^{\text {ns }}$ \\
\hline 250 & $0,3^{\text {ns }}$ & $1,3^{\mathrm{ns}}$ & $13,0^{\mathrm{ns}}$ & $24,0^{\mathrm{ns}}$ & $27,3^{\text {ns }}$ & $29,5^{\text {ns }}$ & $30,0^{\mathrm{ns}}$ & $30,8^{\text {ns }}$ & $31,0^{\mathrm{ns}}$ & $31,0^{\mathrm{ns}}$ & $31,5^{\mathrm{ns}}$ & $32,0^{\mathrm{ns}}$ & $32,0^{\mathrm{ns}}$ & $32,0^{\mathrm{ns}}$ & $32,0^{\mathrm{ns}}$ \\
\hline 500 & $0,0^{\mathrm{ns}}$ & $0,8^{\mathrm{ns}}$ & $14,5^{\text {ns }}$ & $23,3^{\mathrm{ns}}$ & $25,5^{\mathrm{ns}}$ & $27,3^{\mathrm{ns}}$ & $28,3^{\mathrm{ns}}$ & $28,5^{\mathrm{ns}}$ & $29,8^{\mathrm{ns}}$ & $29,8^{\mathrm{ns}}$ & $29,8^{\mathrm{ns}}$ & $29,8^{\mathrm{ns}}$ & $29,8^{\mathrm{ns}}$ & $29,8^{\mathrm{ns}}$ & $29,8^{\mathrm{ns}}$ \\
\hline 1.000 & $0,3^{\mathrm{ns}}$ & $0,5^{\mathrm{ns}}$ & $14,8^{\mathrm{ns}}$ & $23,8^{\mathrm{ns}}$ & $27,0^{\mathrm{ns}}$ & $30,0^{\mathrm{ns}}$ & $30,8^{\mathrm{ns}}$ & $32,0^{\mathrm{ns}}$ & $32,5^{\mathrm{ns}}$ & $32,8^{\mathrm{ns}}$ & $32,8^{\mathrm{ns}}$ & $33,0^{\mathrm{ns}}$ & $33,0^{\text {ns }}$ & $33,0^{\mathrm{ns}}$ & $33,0^{\mathrm{ns}}$ \\
\hline \multicolumn{16}{|c|}{ Z. mays } \\
\hline Controle & $0,0^{\text {ns }}$ & $11,5^{\mathrm{ns}}$ & $20,0^{\mathrm{ns}}$ & $21,8^{\mathrm{ns}}$ & $22,3^{\text {ns }}$ & $22,3^{\text {ns }}$ & $22,3^{\text {ns }}$ & $22,3^{\text {ns }}$ & $22,3^{\text {ns }}$ & $22,3^{\mathrm{ns}}$ & $22,3^{\mathrm{ns}}$ & - & - & - & - \\
\hline 250 & $0,0^{\mathrm{ns}}$ & $7,5^{\mathrm{ns}}$ & $17,5^{\text {ns }}$ & $18,5^{\mathrm{ns}}$ & $18,5^{\mathrm{ns}}$ & $19,0^{\mathrm{ns}}$ & $19,5^{\mathrm{ns}}$ & $19,5^{\text {ns }}$ & $19,5^{\text {ns }}$ & $19,5^{\mathrm{ns}}$ & $19,5^{\text {ns }}$ & - & - & - & - \\
\hline 500 & $0,0^{\text {ns }}$ & $8,0^{\mathrm{ns}}$ & $18,0^{\mathrm{ns}}$ & $20,0^{\mathrm{ns}}$ & $20,3^{\mathrm{ns}}$ & $20,3^{\mathrm{ns}}$ & $20,5^{\mathrm{ns}}$ & $20,8^{\mathrm{ns}}$ & $20,8^{\mathrm{ns}}$ & $20,8^{\mathrm{ns}}$ & $20,8^{\mathrm{ns}}$ & - & - & - & - \\
\hline 1.000 & $0,0^{\mathrm{ns}}$ & $9,8^{\text {ns }}$ & $19,8^{\mathrm{ns}}$ & $21,5^{\mathrm{ns}}$ & $21,5^{\mathrm{ns}}$ & $21,8^{\mathrm{ns}}$ & $22,0^{\mathrm{ns}}$ & $22,5^{\mathrm{ns}}$ & $22,5^{\mathrm{ns}}$ & $22,5^{\mathrm{ns}}$ & $22,5^{\text {ns }}$ & - & - & - & - \\
\hline
\end{tabular}

* $\mathrm{G}=$ germinação média/ns = não significativo. 
TABELA 3: Velocidade média de germinação das sementes de Lactuca sativa, Lycopersicum esculentum e Zea mays, sob o efeito do extrato etanólico das folhas de C. sabulicola. Barreiras, Bahia, Brasil, 2010-2012.

\begin{tabular}{|c|c|c|c|c|c|c|c|c|c|c|c|c|c|c|c|}
\hline \multirow{3}{*}{$\begin{array}{l}\text { Concentração } \\
\left(\mathrm{mg} \cdot \mathrm{L}^{-1}\right)\end{array}$} & \multicolumn{14}{|c|}{ L. sativa } & \multirow[b]{3}{*}{15} \\
\hline & \multicolumn{14}{|c|}{ G.Dias $^{-1}$} & \\
\hline & 1 & 2 & 3 & 4 & 5 & 6 & 7 & 8 & 9 & 10 & 11 & 12 & 13 & 14 & \\
\hline Controle & $45,5^{\text {ns }}$ & $47,8^{\mathrm{ns}}$ & $49,0^{\mathrm{ns}}$ & $49,0^{\mathrm{ns}}$ & $49,0^{\mathrm{ns}}$ & $49,0^{\mathrm{ns}}$ & $49,0^{\mathrm{ns}}$ & - & - & - & - & - & - & - & - \\
\hline 250 & $45,8^{\mathrm{ns}}$ & $48,0^{\mathrm{ns}}$ & $49,3^{\mathrm{ns}}$ & $49,8^{\mathrm{ns}}$ & $49,8^{\mathrm{ns}}$ & $49,8^{\text {ns }}$ & $49,8^{\text {ns }}$ & - & - & - & - & - & - & - & - \\
\hline 500 & $44,8^{\mathrm{ns}}$ & $47,3^{\mathrm{ns}}$ & $49,5^{\mathrm{ns}}$ & $49,8^{\mathrm{ns}}$ & $49,8^{\mathrm{ns}}$ & $49,8^{\mathrm{ns}}$ & $49,8^{\text {ns }}$ & - & - & - & - & - & - & - & - \\
\hline 1.000 & $46,8^{\mathrm{ns}}$ & $48,8^{\mathrm{ns}}$ & $49,8^{\mathrm{ns}}$ & $49,8^{\mathrm{ns}}$ & $49,8^{\mathrm{ns}}$ & $49,8^{\text {ns }}$ & $49,8^{\text {ns }}$ & - & - & - & - & - & - & - & - \\
\hline \multicolumn{16}{|c|}{ L. esculentum } \\
\hline Controle & $0,0^{\mathrm{ns}}$ & $1,5^{\mathrm{ns}}$ & $11,5^{\mathrm{ns}}$ & $23,0^{\mathrm{ns}}$ & $25,0^{\mathrm{ns}}$ & $27,5^{\mathrm{ns}}$ & $28,0^{\mathrm{ns}}$ & $28,5^{\mathrm{ns}}$ & $28,8^{\mathrm{ns}}$ & $29,3^{\mathrm{ns}}$ & $29,5^{\mathrm{ns}}$ & $29,5^{\mathrm{ns}}$ & $29,8^{\text {ns }}$ & $29,8^{\text {ns }}$ & $29,8^{\mathrm{ns}}$ \\
\hline 250 & $0,0^{\mathrm{ns}}$ & $1,8^{\mathrm{ns}}$ & $12,3^{\mathrm{ns}}$ & $22,0^{\mathrm{ns}}$ & $25,0^{\mathrm{ns}}$ & $27,5^{\text {ns }}$ & $28,0^{\text {ns }}$ & $28,5^{\text {ns }}$ & $28,5^{\text {ns }}$ & $29,0^{\text {ns }}$ & $29,3^{\text {ns }}$ & $29,5^{\text {ns }}$ & $29,5^{\text {ns }}$ & $29,8^{\text {ns }}$ & $29,8^{\mathrm{ns}}$ \\
\hline 500 & $0,3^{\text {ns }}$ & $1,3^{\mathrm{ns}}$ & $11,8^{\mathrm{ns}}$ & $23,0^{\mathrm{ns}}$ & $26,0^{\mathrm{ns}}$ & $28,5^{\mathrm{ns}}$ & $30,5^{\text {ns }}$ & $31,0^{\mathrm{ns}}$ & $31,8^{\mathrm{ns}}$ & $31,8^{\mathrm{ns}}$ & $31,8^{\mathrm{ns}}$ & $32,8^{\mathrm{ns}}$ & $32,8^{\mathrm{ns}}$ & $33,0^{\mathrm{ns}}$ & $33,0^{\mathrm{ns}}$ \\
\hline 1.000 & $0,0^{\mathrm{ns}}$ & $0,5^{\mathrm{ns}}$ & $13,5^{\mathrm{ns}}$ & $22,3^{\mathrm{ns}}$ & $25,0^{\mathrm{ns}}$ & $26,5^{\mathrm{ns}}$ & $28,0^{\mathrm{ns}}$ & $28,8^{\mathrm{ns}}$ & $29,5^{\text {ns }}$ & $29,8^{\text {ns }}$ & $30,5^{\text {ns }}$ & $31,3^{\text {ns }}$ & $31,5^{\text {ns }}$ & $31,8^{\mathrm{ns}}$ & $31,8^{\mathrm{ns}}$ \\
\hline \multicolumn{16}{|c|}{ Z. mays } \\
\hline Controle & $0,0^{\mathrm{ns}}$ & $11,5^{\text {ns }}$ & $20,0^{\mathrm{ns}}$ & $21,8^{\mathrm{ns}}$ & $22,3^{\mathrm{ns}}$ & $22,3^{\mathrm{ns}}$ & $22,3^{\text {ns }}$ & $22,3^{\mathrm{ns}}$ & $22,3^{\mathrm{ns}}$ & $22,3^{\mathrm{ns}}$ & $22,3^{\mathrm{ns}}$ & - & - & - & - \\
\hline 250 & $0,0^{\mathrm{ns}}$ & $11,0^{\mathrm{ns}}$ & $20,8^{\mathrm{ns}}$ & $22,0^{\mathrm{ns}}$ & $22,3^{\mathrm{ns}}$ & $22,3^{\text {ns }}$ & $22,3^{\mathrm{ns}}$ & $22,3^{\text {ns }}$ & $22,3^{\text {ns }}$ & $22,3^{\text {ns }}$ & $22,3^{\text {ns }}$ & - & - & - & - \\
\hline 500 & $0,0^{\mathrm{ns}}$ & $8,8^{\mathrm{ns}}$ & $18,5^{\mathrm{ns}}$ & $20,5^{\mathrm{ns}}$ & $20,5^{\mathrm{ns}}$ & $21,0^{\mathrm{ns}}$ & $21,0^{\mathrm{ns}}$ & $21,0^{\mathrm{ns}}$ & $21,0^{\mathrm{ns}}$ & $21,0^{\mathrm{ns}}$ & $21,0^{\mathrm{ns}}$ & - & - & - & - \\
\hline 1.000 & $0,0^{\mathrm{ns}}$ & $10,8^{\mathrm{ns}}$ & $17,8^{\mathrm{ns}}$ & $19,5^{\mathrm{ns}}$ & $20,5^{\mathrm{ns}}$ & $20,8^{\mathrm{ns}}$ & $20,8^{\mathrm{ns}}$ & $20,8^{\mathrm{ns}}$ & $20,8^{\mathrm{ns}}$ & $20,8^{\mathrm{ns}}$ & $20,8^{\mathrm{ns}}$ & - & - & - & - \\
\hline
\end{tabular}

* $\mathrm{G}=$ germinação média/ns = não significativo.

TABELA 4: Índice de velocidade de germinação das sementes de Lactuca sativa, Lycopersicum esculentum e Zea mays, submetidas aos extratos etanólicos de Copaifera sabulicola. Barreiras, Bahia, Brasil, 2010-2012.

\begin{tabular}{cccc}
\hline \multicolumn{4}{c}{ Extrato do Caule } \\
Concentração (mg.L $\left.\mathbf{~}^{-1}\right)$ & L. sativa & L. esculentum & Z. mays \\
\hline Controle & $47,04 \mathrm{~A} \pm 0,34$ & $7,98 \mathrm{~A} \pm 0,64$ & $9,12 \mathrm{~A} \pm 0,26$ \\
250 & $47,83 \mathrm{~A} \pm 0,84$ & $8,72 \mathrm{~A} \pm 0,65$ & $6,85 \mathrm{~B} \pm 0,66$ \\
500 & $45,75 \mathrm{~A} \pm 1,26$ & $8,20 \mathrm{~A} \pm 0,12$ & $7,45 \mathrm{~B} \pm 0,60$ \\
1.000 & $47,83 \mathrm{~A} \pm 0,71$ & $8,89 \mathrm{~A} \pm 0,54$ & $8,40 \mathrm{~A} \pm 0,64$ \\
\hline \multicolumn{4}{c}{ Extrato das Folhas } \\
\hline Controle & $47,24 \mathrm{~A} \pm 0,38$ & $8,03 \mathrm{~A} \pm 0,64$ & $9,12 \mathrm{~A} \pm 0,26$ \\
250 & $47,47 \mathrm{~A} \pm 0,52$ & $8,07 \mathrm{~A} \pm 0,35$ & $9,11 \mathrm{~A} \pm 0,44$ \\
1.000 & $46,86 \mathrm{~A} \pm 0,91$ & $8,61 \mathrm{~A} \pm 0,57$ & $8,21 \mathrm{~A} \pm 1,06$ \\
& $48,13 \mathrm{~A} \pm 0,45$ & $8,15 \mathrm{~A} \pm 0,54$ & $8,02 \mathrm{~A} \pm 0,87$ \\
\hline
\end{tabular}

Médias seguidas da mesma letra, nas colunas, não diferem significativamente pelo teste de Scott-Knott ( $\mathrm{p} \leq 0,05)$. Média \pm erro. 
No crescimento radicular de L. esculentum, o extrato do caule, na concentração $500 \mathrm{mg} \cdot \mathrm{L}^{-1}$ causou estímulo de $66 \%$ e as concentrações 250 e 1.000 mg. $\mathrm{L}^{-1}$ causaram estímulo médio de $153 \%$, em relação ao controle (Figura 1). Já no extrato foliar, as concentrações promoveram estímulo médio de $85 \%$ no crescimento da radícula (Figura 1). No crescimento do hipocótilo, o extrato do caule, na concentração $250 \mathrm{mg} . \mathrm{L}^{-1}$, promoveu estímulo de $61 \%$ (Figura 1). Contudo, não foi constatada diferença estatística para o extrato foliar sobre o hipocótilo de L. esculentum (Figura 1).

No crescimento das plântulas de Z. mays, os resultados não diferem estatisticamente do controle, ainda que se tenha observado inibição média de 25 e 32\% no crescimento da raiz primária, causada pelo extrato do caule e das folhas, respectivamente (Figura 1).

FIGURA 1: Efeito dos extratos etanólicos do caule (EEC) e das folhas (EEF) de Copaifera sabulicola, no crescimento da radícula (CR) e do hipocótilo $(\mathrm{CH})$ de Lactuca sativa e Lycopersicum esculentum, e no crescimento da raiz primária (CRP) e do coleóptilo (CC) de Zea mays. Barreiras, Bahia, Brasil, 2010-2012.

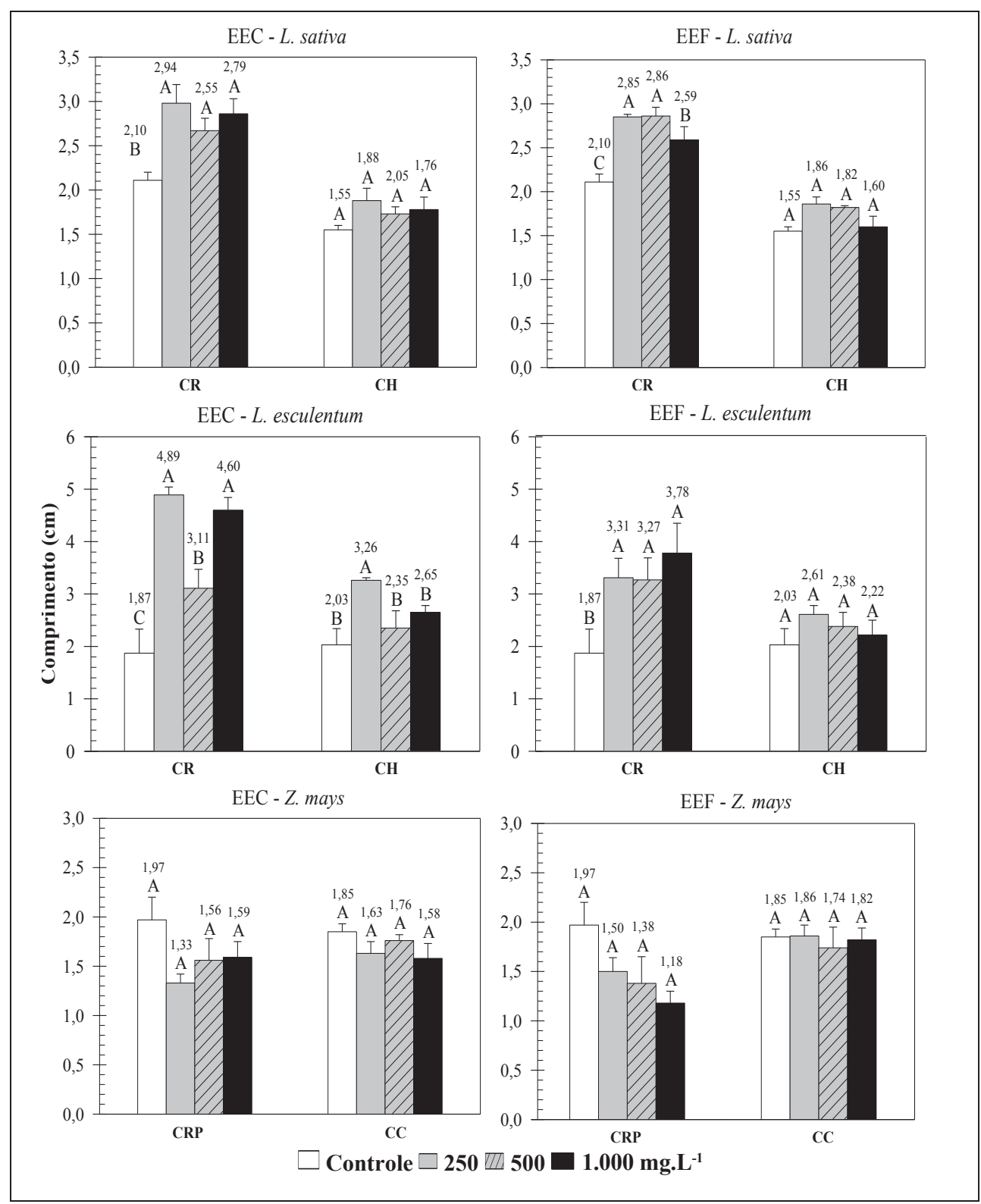

Médias seguidas da mesma letra, nas colunas, não diferem significativamente pelo teste de Scott-Knott $(\mathrm{p} \leq 0,05)$. 


\section{Discussão}

A partir das análises dos dados, constatou-se o potencial e efeito alelopático dos extratos etanólicos do caule e das folhas de C. sabulicola, tanto no processo germinativo quanto no crescimento inicial das espécies ensaiadas. Os resultados indicaram diferenças quanto ao padrão de resposta entre as eudicotiledôneas e a monocotiledônea testadas, as quais sofreram efeito estimulante e inibitório, respectivamente, provavelmente relacionado às suas especificidades biológicas.

Em outro estudo com algumas espécies da família Leguminosae (Bauhinia guianensis Aubl., B. macrostachya Benth., Bowdichia virgilioides (segundo o IPNI) Kunth., Dialium guianensis Aubl., Inga edulis Mart., Parkia pendula (Willd.) Benth. ex Walp., Platimenia reticulata (segundo o IPNI) Benth. e Swartzia multijuga Vog.), Mourão-Júnior e Souza-Filho (2010) obtiveram resultados divergentes quando avaliaram o efeito do extrato bruto hidroalcoólico (metanol e água na proporção 7:3), evidenciando efeitos inibitórios na PG de outras eudicotiledôneas (Mimosa pudica L. e Senna obtusifolia (L.) Irwin \& Barneby). Contudo, esses efeitos foram superiores, em média $28 \%$, aos efeitos alelopáticos dos extratos de C. sabulicola sobre a PG de Z. mays.

Assim como no presente estudo, Manoel et al. (2009) não verificaram diferenças significativas para PG de L. esculentum, quando testaram extratos aquosos das folhas de pata-de-vaca (Bauhinia forficata Link Leguminosae). Entretanto, foram verificados atrasos na VMG de L. esculentum, onde o extrato de folhas secas de $B$. forficata promoveu efeito inibitório em todas as concentrações utilizadas $(25,50,75$ e 100\%), causando um atraso médio de $10 \%$, em relação ao controle.

Ressalta-se que, os efeitos alelopáticos podem ser menos intensos na porcentagem final de germinação e mais intensos na velocidade de germinação, como evidenciado também por Oliveira et al. (2012) ao verificarem o potencial alelopático de extratos aquosos de cascas de mulungu (Erythrina velutina Willd. - Leguminosae) sobre L. sativa, causando redução da velocidade de germinação desta eudicotiledônea. Tal fato não está de acordo com as variações na VMG de L. sativa e Z. mays na presença dos extratos de C. sabulicola, sendo essas variações menos evidentes quando comparadas à $\mathrm{PG}$ destas espécies (Tabelas 1, 2 e 3).

Quanto ao IVG, produto entre o somatório do número de sementes germinadas a cada dia e o número de dias decorridos, destaca-se apenas o efeito alelopático sobre Z. mays, o qual foi promovido pelo o extrato do caule. Considerando-se que, quanto maior o índice, maior será a velocidade de germinação, as variações negativas no IVG de Z. mays refletiram, portanto, na diminuição significativa do vigor germinativo de suas sementes, nas menores concentrações do extrato do caule (Tabela 4).

É interessante salientar que as divergências entre os resultados das literaturas supracitadas e do presente trabalho podem estar relacionadas às concentrações $\mathrm{e}$ diferenças no grau de polaridade dos extratos testados (alcoólico e aquoso), além de tratarem de espécies distintas, com características fitoquímicas específicas. Deste modo, o tipo de extração pode selecionar conjuntos específicos de moléculas orgânicas, de maior ou menor afinidade com os solventes utilizados para o preparo (etanol/metanol/água destilada).

Neste contexto, Souza-Filho et al. (2010) analisaram a atividade alelopática de três espécies de Copaifera L., sobre duas plantas espontâneas, malicia (M. pudica) e mata-pasto (S. obtusifolia). Comparando a polaridade do extrato hexânico (apolar) e etanólico (alta polaridade), dos galhos, das cascas e folhas, esses autores constaram diferenças significativas. Extratos etanólicos de $C$. martii e $C$. reticulata apresentaram maior potencial para inibir a germinação e o crescimento da raiz, sendo que as substâncias apolares presentes nestas espécies estão mais relacionadas com inibições do desenvolvimento da raiz do que da germinação. Para $C$. duckei, os extratos hexânicos foram os mais eficazes, em relação aos etanólicos.

Em $L$. sativa e $L$ esculentum, o crescimento das plântulas foi mais sensível à atividade alelopática do que o processo germinativo, principalmente para $L$. esculentum. Destacam-se maiores efeitos no crescimento radicular do que no crescimento do hipocótilo, o que pode estar relacionado ao maior tempo e superfície de 
contato da radícula com o papel filtro impregnado com os tratamentos, além de ser uma estrutura de característica anatômica mais eficiente à absorção. Entretanto, para $Z$. mays, considera-se que o processo germinativo foi mais sensível à atividade alelopática, uma vez que não foram verificadas diferenças estatísticas $(\mathrm{p} \leq 0,05)$ no tamanho das plântulas desta espécie, em relação ao controle.

Considerando-se a grande variedade de metabólitos da classe dos terpenos ocorrentes no gênero Copaifera L. (VEIGA-JÚNIOR; PINTO, 2002), há relatos na literatura sobre o comportamento aleloquímico de lactonas sequisterpênicas sobre $L$. sativa, as quais estimularam o crescimento da raiz, porém inibiram o crescimento do hipocótilo dessa espécie (MACIAS et al., 2006). Assim, é provável que esse comportamento possa estar relacionado às substâncias, como terpenos, presentes nos extratos etanólicos de C. sabulicola, ao estimularem o crescimento inicial, sobretudo o radicular, das eudicotiledôneas testadas, como evidenciado na Figura 1.

Os extratos etanólicos de C. sabulicola não causaram irregularidades nas plântulas das espécies teste, já que as anormalidades não foram significativas, em relação ao controle (dados não mostrados), o que reduz a probabilidade dos extratos serem citotóxicos. Entretanto, a ocorrência de irregularidades nas plântulas de monocotiledônea foi mais evidente do que nas eudicotiledôneas ensaiadas, apresentando atrofiamento, principalmente no sistema radicular. Vale destacar que, avaliações das anormalidades de plântulas constituem um importante recurso para aferir a atividade alelopática, sendo a necrose da radícula o efeito mais comum (FERREIRA; ÁQUILA, 2000).

Com base nos resultados, o extrato do caule de $C$. sabulicola mostrou maior eficácia às espécies ensaiadas. A diferença de resultados entre os extratos do caule e das folhas da espécie pode ser justificada devido às concentrações de metabólitos secundários variarem de acordo com o órgão vegetal, o que também foi corroborado por Souza-Filho et al. (2010), quando verificaram variações na atividade alelopática de diferentes copaíferas em função da parte da planta (galhos, cascas e folhas).

Os efeitos alelopáticos decorrente dos extratos de C. sabulicola provavelmente são indícios da ocorrência de metabólitos secundários com função aleloquímica, concordando com os relatos na literatura da presença princípios ativos em algumas espécies deste gênero (VEIGA-JÚNIOR; PINTO, 2002; PEREIRA et al., 2008; DEUS et al., 2009; LEANDRO et al., 2012).

A identificação de metabólitos secundários, como: diterpenos e sesquiterpenos, e óleos essenciais em Copaifera L., tornou algumas espécies deste gênero fonte de pesquisas para o tratamento de várias doenças. A presença de terpenos no gênero parece justificar os efeitos alelopáticos de C. sabulicola. Estes compostos estão relacionados à repelência aos herbívoros, proteção contra doenças e atração de insetos polinizadores (CONSTANTINO, 2008; TAIZ; ZEIGER, 2013).

Os resultados gerados no presente estudo são os primeiros relatos na literatura referentes às propriedades alelopáticas de C. sabulicola. Portanto, além de incrementar a produção científica, esta pesquisa vem subsidiar outros estudos relacionados à química de produtos naturais, pela busca de substâncias que agridam menos o meio ambiente e a saúde pública. Futuros estudos podem ser realizados quanto à caracterização química dos extratos, fracionamento e isolamento de compostos de C. sabulicola, sobretudo testes em campo e com outras espécies teste.

A partir dos resultados, foi possível concluir que, os extratos etanólicos do caule e das folhas de $C$. sabulicola apresentaram potencial alelopático sobre o desenvolvimento inicial de L. sativa e L. esculentum. O extrato do caule, em todas as concentrações, promoveu o estímulo da germinação e do crescimento radicular de L. sativa, bem como o crescimento radicular (independente da concentração) e do hipocótilo (250 mg. $\mathrm{L}^{-1}$ ) de L. esculentum, enquanto que o extrato das folhas, em todas as concentrações, estimulou apenas o crescimento radicular dessas espécies. Ambos os extratos apresentaram efeito alelopático sobre a germinação de Z. mays, causando inibições significativas nas concentrações de 250 e $500 \mathrm{mg} . \mathrm{L}^{-1}$ do extrato do caule e de $1.000 \mathrm{mg} \cdot \mathrm{L}^{-1}$ do extrato foliar.

\section{Agradecimento}

À Fundação de Amparo de Pesquisa do estado da Bahia (FAPESB) pelo apoio financeiro. 


\section{Referências}

BARNES, R. A.; SOEIRO, O. M. The alkaloids of Croton salutares. Phytochemistry, Leiden, v. 20, p. 543-544, 1981.

BORELLA, J.; PASTORINI, L. H. Influência alelopática de Phytolacca dioica L. na germinação e crescimento inicial de tomate e picão-preto. Biotemas, Florianópolis, v. 22, p. 67-75, 2009.

BRASIL - MINISTÉRIO DA AGRICULTURA E DA REFORMA AGRÁRIA. Regras para a análise de sementes. Brasília: SNDA/ DNDV/CLAV, 1992. 365 p.

CONSTANTINO, M. G. Terpenos e esteroides. In:CONSTANTINO, M. G. (Ed.). Química orgânica. 1. ed. São Paulo: LTC, 2008. p. 351-367.

COSTA, J. A. S.; QUEIROZ, L. P. Copaifera sabulicola (Leguminosae), uma nova espécie do Cerrado brasileiro. Rodriguésia, Rio de Janeiro, v. 58, p. 393-396, 2007.

DEUS, R. J. A.; CARVALHO, A. S. C.; BANNA, D. A. D. S.; ARRUDA, M. S. P.; ALVES, C. N.; SANTOS, A. S. Efeito fungitóxico in vitro do óleo resina e do óleo essencial de copaíba (Copaifera multijuga Hayne). Revista Brasileira de Plantas Medicinais, Botucatu, v. 11, p. 347-353, 2009.

DURAN, J. M.; TORTOSA, M. E. The effect of mechanical and chemical scarification germination of charlock $S$. arvensis. Seed Science and Technology, Zurich, v. 13, p. 155-163, 1985.

EUCLYDES, R. F. Manual de utilização do programa SAEG (Sistema para Análises Estatísticas e Genéticas). Viçosa: UFV, 1997. $150 \mathrm{p}$.

FERREIRA, A. G.; ÁQUILA, M. E. A. Alelopatia: uma área emergente da ecofisiologia. Revista Brasileira de Fisiologia Vegetal, Campinas, v. 12, p. 175-204, 2000.

GATTI, A. B.; CRISTINA, S.; PEREZ, J. G. de A.; FERREIRA, A. G. Avaliação da atividade alelopática de extratos aquosos de folhas de espécies de Cerrado. Revista Brasileira de Biociências, Porto Alegre, v. 5, p. 174-176, 2007.

GERIS, R.; SILVA, I. G.; SILVA, H. H. G.; BARISON, A.; RODRIGUES-FILHO, E.; FERREIRA, A. G. Diterpenoids from Copaifera reticulata Ducke with larvicidal activity against Aedes aegypti (L.) (Diptera, Culicidae). Revista do Instituto de Medicina Tropical de São Paulo, São Paulo, v. 50, p. 25-28, 2008.

GOMES, F. M.; FORTES, A. M. T.; SILVA, J.; BONAMIGO, T.; PINTO, T. T. Efeito alelopático da fitomassa de Lupinus angustifolius (L.) sobre a germinação e desenvolvimento inicial de Zea mays (L.) e Bidens pilosa (L.). Revista Brasileira de Agroecologia, Porto Alegre, v. 8, p. 48-56, 2013.

LEANDRO, L. M.; VARGAS, F. de S.; BARBOSA, P. C. S.; NEVES, J. K. O.; SILVA, J. A. da; VEIGA-JUNIOR, V. F. da. Chemistry and biological activities of terpenoids from copaiba (Copaifera spp.) Oleoresins. Molecules, Basel, v. 17, p. 3866-3889, 2012.

MACIAS, F. A.; FERNANDEZ, A.; VARELA, R. M.; MOLINILLO, J. M. G.; TORRES, A.; ALVES, P. L. C. A. 2006. Sesquiterpene lactones as allelochemicals. Journal of Natural Products, Columbus, v. 69, p. 795-800, 2006.

MAGUIRE, J. D. Speed of germination-aid in selection evaluation for seedling emergence and vigour. Crop Science, Madison, v. 2, p. 176-199, 1962.

MANOEL, D. D.; DOICHE, C. F. R.; FERRARI, T. B.; FERREIRA, G. Atividade alelopática dos extratos fresco e seco de folhas de barbatimão (Stryphnodendron adstringens (Mart.) Coville) e pata-de-vaca (Bauhinia forficata link) sobre a germinação e desenvolvimento inicial de plântulas de tomate. Semina: Ciências Agrárias, Londrina, v. 30, p. 63-70, 2009.

MELOS, J. L. R.; SILVA, L. B.; PERES, M. T. L. P.; MAPELI, A. M.; FACCENDA, O.; ANJOS, H. H.; TORRES, T. G.; TIVIROLI, S. C.; BATISTA, A. L.; ALMEIDA, F. G. N.; FLAUZINO, N. S., TIBANA, L. A.; HESS, S. C.; HONDA, N. K. Constituintes químicos e avaliação do potencial alelopático de Adiantum tetraphyllum Humb. \& Bonpl. ex. Willd (Pteridaceae). Química Nova, São Paulo, v. 30, p. 292-297, 2007.

MOURÃO-JÚNIOR, M.; SOUZA-FILHO, A. P. S. Diferenças no padrão da atividade alelopática em espécies da família leguminosae. Planta Daninha, Viçosa, v. 28, p. 939-951, 2010.

OLIVEIRA, A. K.; COELHO, M. F. B.; MAIA, S. S. S.; DIÓGENES, F. E. P.; MEDEIROS-FILHO, F. M. Alelopatia de extratos de diferentes órgãos de mulungu na germinação de alface. Horticultura Brasileira, Brasília, v. 30, p. 480-483, 2012.

OLIVEIRA, N. S.; MERCADANTE, M. O.; LOPES, P. S. N.; GOMES, I. A. C.; GUSMÃO, E.; RIBEIRO, L. M. Efeito alelopático dos extratos aquoso e etanólico de Jatobá do Cerrado. Unimontes Científica, Montes Claros, v. 4, p. 143-151, 2002.

PEREIRA, F. J.; MARTINS, F. T.; CORRÊA, R. S.; MOREIRA, M. E. C.; COSTA, A. M. D. D.; DOS SANTOS, M. H.; POLO, M.; BARBOSA, L. C. A. Isolamento, composição química e atividade anti-inflamatória do óleo essencial do pericarpo de Copaifera langsdorffii Desf. de acordo com hidrodestilações sucessivas. Latin American Journal of Pharmacy, Buenos Aires, v. 27, p. 369-374, 2008.

PERES, M. T. L. P.; MAPELI, A. M.; FACCENDA, O.; GOMES, A. T.; HONDA, N. K. Allelopathic potential of orsellinic acid derivatives. Brazilian Archives of Biology and Technology, Curitiba, v. 52, p. 1019-1026, 2009.

SOUZA, A. B.; SOUZA, M. G. M. de; MOREIRA, M. A.; MOREIRA, M. R.; FURTADO, N. A. J. C.; MARTINS, C. H. G.; BASTOS, J. K.; SANTOS, R. A. dos; HELENO, V. C. G.; AMBROSIO, S. R.; VENEZIANI, R. C. S. Antimicrobial evaluation of diterpenes from Copaifera langsdorffii oleoresin against periodontal anaerobic bacteria. Molecules, Basel, v. 16, p. 9611-9619, 2011.

SOUZA, L. S.; VELINI, E. D.; MARTINS, D.; ROSOLEM, C. A. Efeito alelopático de capim braquiária (Brachiaria decumbens) sobre o crescimento inicial de sete espécies de plantas cultivadas. Planta Daninha, Viçosa, v. 24, p. 657-668, 2006.

SOUZA-FILHO, A. P. S.; GURGEL, E. S. C.; QUEIROZ, M. S. M.; SANTOS, J. U. M. Atividade alelopática de extratos brutos de três espécies de Copaifera (Leguminosae-Caesalpinioideae). Planta Daninha, Viçosa, v. 28, p. 743-751, 2010.

TAIZ, L.; ZEIGER, E. Metabolismo secundário e defesa vegetal. In: TAIZ, L.; ZEIGER, E. (Ed.). Fisiologia vegetal. 5. ed. Porto Alegre: Artimed, 2013. p. 369-396.

VEIGA-JÚNIOR, V. F.; PINTO, A. C. O gênero Copaifera L. Química Nova, São Paulo, v. 25, p. 273-286, 2002.

VEIGAS-JÚNIOR, C. Terpenos com atividade inseticida: uma alternativa para o controle químico de insetos. Química Nova, São Paulo, v. 26, p. 390-400, 2003. 